\title{
Model papers for The Knowledge Engineering Review
}

This is the last issue of the first international volume of The Knowledge Engineering Review. The volume makes interesting reading, both for the range of topics covered and the range of paper styles that we have been able to experiment with. Our reason for being such a broad spectrum journal is partly because of the breadth of intended audience-engineers, designers, researchers, teachers, students and so on, but also because the Review has a clear aim; to foster the development of knowledge engineering as a sound engineering discipline.

The Review is not a primary research journal (of which there are now many) but aims at a broad perspective. Volume 3 will build upon the eclectic style of volume 2, and maintain the commitments to breadth and depth. We shall continue to seek authoritative, foundational surveys of technical topics; critical reviews of developing trends and techniques; case studies; commentary and discussion, etc. We are keen to provide information to, and a common forum for, workers in all fields - whether medicine, law, engineering, business... We are opposed to the development of narrow technical specialisms and against the divorce of knowledge engineering from its scientific roots in artificial intelligence and cognitive science.

How do these grand aims translate into tangible publications? What guidance can we give to authors preparing material for such a heterogeneous publication? There are several types of paper in the current volume which serve different but equally valuable functions. We therefore propose to encourage some of these forms explicitly. A number of "model plans" are offered below to illustrate the kinds of paper that the we would like to see. The specific formats are not mandatory, and authors are encouraged to develop others, but we hope that some of their features and the general emphasis on clear structure will be helpful in the preparation of submissions.

\section{Analysis papers}

These papers are expected to be high quality, foundational surveys providing a balanced but critical presentation of the primary concepts in an area. Authors are encouraged to make a personal contribution by their informed assessment of progress in an area, or by a technical or conceptual analysis. If the literature on the topic is substantial then annotated bibliographies of representative and important reference material are highly desirable.

- Introduction and overview

- Summary of primary literature associated with the topic

- Critical assessment of major concepts, important directions in research and/or development etc.

- Discussion of implications for practical engineering

- Bibliography/further reading

\section{Examples in earlier issues}

Paul Cohen (USA). "The control of reasoning under uncertainty, a discussion of some programs" vol. 2 no 1.

Phil Slatter (UK). "Cognitive emulation in expert system design" vol. 2 no 1.

Jean-Pierre Laurent (France). "Types of control structures in expert systems" vol. 2 no 2.

Alessandro Saffiotti (Italy). "AI views of the treatment of uncertainty" vol. 2 no 2.

S P Stenton (UK). "Dialogue management for cooperative knowledge based systems" vol. 2 no 2. 


\section{Applications and country surveys}

The Review will also publish other kinds of survey. These will include critical assessments of the application of knowledge based systems and AI to important application areas and the development of knowledge engineering and applied AI in different countries. These surveys are, however, normally only of interest if important trends or developments are identified, or experiences are drawn out which are of interest to an international audience. Discussion of applications which challenge the state of the art in knowledge engineering, or raise substantive issues for AI, are of particular interest.

- Background-characteristics and constraints of the application area

- Survey of work

- Critical assessment of trends; progress; prospects

- Bibliography/further reading

\section{Examples of area surveys}

Con Connell (UK). "The current impact of expert systems on the accounting profession and some reasons for hesitancy in the adoption of such systems" vol. 2 no 3.

W Gale (USA). "Statistical applications of artificial intelligence and knowledge engineering" vol. 2 no 4.

N S Walker and J Fox (UK). "Knowledge based interpretation of images: a biomedical perspective" vol. 2 no 4 .

\section{Examples of country surveys}

Alex d'Agapeyeff and C J B Hawkins (UK). "Expert systems in UK business: a critical assessment" vol. 2 no 3.

Fumihiko Mori (Japan). "Expert systems in business, a Japanese experience" vol. 2 no 3.

\section{Case studies}

The value of case studies will be judged on the degree to which they draw out general lessons from experience with particular tools, techniques, or applications. The papers should provide enough background on the application domain to permit readers to distinguish general observations from idosyncratic features of the domain. Loose anecdotal discussion of cases is not normally appropriate; formal evaluations of performance or design features, and systematic analyses of tools and techniques are highly desirable.

- Introduction and overview

- Background to the project

- Project description

- General lessons. Assessment of tools, techniques etc.

\section{Examples}

Jean-Pierre Laurent, J Ayel, F Thome, D Ziebelin (France). “Comparative evaluation of three expert system development tools: Kee, knowledge craft, art" vol. 1 no 4.

V Robinson, N W Hardy, D P Barnes, C J Price, M H Lee (UK). "Experiences with a knowledge engineering toolkit: an assessment in industrial robotics" vol. 2 no 1.

S D Ward and D Sleeman (UK). "Learning to use the S.1 knowledge engineering tool"; M S Lan, R M Panos, and M S Balban (USA). "Experience using S.1: an expert system for newspaper printing press configuration" vol. 2 no 4 . 


\section{Commentaries}

Observations by practitioners and others on how research and development is being, or should be, transferred into commercial and industrial practice are of particular interest but any well-informed commentaries which are likely to be of interest to a technical audience will be considered.

\section{Examples}

Bernard P Wess Jr. (USA). "Commentary on the commercialization of knowledge engineering: enterprise and product development" vol. 2 no 3.

Leland Teschler (USA). "Trends in the marketing of expert system technology" vol. 2 no 3.

S C Laufmann (USA). "A strategy for near-term success using knowledge-based systems" vol. 2 no 3 .

\section{Critiques/debates}

The purpose of these articles is to dissent from received wisdom, debunk fashions, demand recognition for unfashionable concepts etc. Critiques may be colourful but should always be well informed and carefully prepared.

- Precis of principal features of field

- Argued objections

- Discussions of practical implications

- Bibliography

\section{Examples}

B Bloomfield (UK). "Capturing expertise by rule induction"; I Bratko and D Michie (Jugoslavia and UK). "Some comments on rule induction"; B Bloomfield (UK). "A reply to Bratko and Michie" vol. 2 no 1.

Richard Susskind (UK). "Critical note: artificial intelligence and the law" vol. 2 no 3.

\section{Book reviews}

The Review tends to publish reviews of books that deal with integrated topics rather than, say, proceedings of research conferences. The typical length of a book review is approximately 1500 2000 words, of which approximately half is general background and discussion and half commentary on the book. Contact the editor for a list of books currently available for review.

\section{Other types of article}

The editor welcomes approaches from anyone interested in contributing material on any topic which may be of general interest to the knowledge engineering community, and is happy to comment on proposals or outlines in anticipation of full preparation. 